\title{
STRUKTUR KOMUNITAS MANGROVE DI KELURAHAN TONGKAINA MANADO
}

\author{
(Structure Community of Mangrove at Tongkaina Village, Manado)
}

\author{
Juwinda Sasauw ${ }^{1^{\star}}$, Janny D. Kusen ${ }^{1}$, Joshian N.W. Schaduw ${ }^{1}$ \\ 1. Program Studi IImu Kelautan, Fakultas Perikanan dan IImu Kelautan, Universitas Sam \\ Ratulangi, Manado \\ e-mail : juwindasasauw@yahoo.com
}

Manggroves appearences as unique and specific vegetation because the capability of living at an extreme area that have high salinity concentration. Manggroves also mentioned as tidal plant because its physiologically development mostly influenced by tidal. The reesearch had been done by using quadrant transect line method through determined 3 (three) observation stasiun for sample gathering. To knew the mangrove condition, therefore Species Density, Species Frequencies, Domination, Importan Value Index and Diversity were measured. Beside that the environment variability such as temperature, salinity adn substrate type at Bahowo Subvillage were measured as well. The results of this research had been showed that the highest density of mangrove species was Rhizopora apiculata as well as Frequencies Value, whereas the highest Domination value was Sonneratia alba. The mangroves Sub-village Diversity had been shown the low value. The water temperature of Bahowo Sub-village ranged from $29-30$ ${ }^{\circ} \mathrm{C}$ and salinity ranged from $29-30 \mathrm{ppt}$, whereas substrate type mostly muddy, therefore the Rhizophora apiculata was frequently found that compared by another species.

Keywords: Condition, Mangroves, Community Structure, Tongkaina Vilage

Mangrove merupakan tumbuhan yang unik dan khas karena mampu bertahan hidup pada daerah yang ekstrim dengan kadar salinitas yang tinggi. Mangrove juga sering disebut dengan tumbuhan pasang-surut karena pertumbuhanya dipengaruhi oleh pasang-surut. Penelitian dilakukan dengan menggunakan metode line transek kuadran dengan menentukan tiga titik pengamatan (stasiun) pengambilan sampel, dan untuk mengetahui kondisi mangrove maka dilakukan perhitungan kerapatan jenis, frekuensi jenis, penutupan jenis, dominasi, indeks nilai penting dan keanekaragaman. Untuk fariabel lingkungan dilakukan beberapa pengukuran yaitu pengukuran suhu, salinitas dan juga melihat tipe substrat yang ada di Kampung Bahowo. Dari hasil penelitian, diketahui bahwa jenis mangrove yang memiliki nilai kerapatan tertinggi yaitu Rhizophora apiculata, dan untuk nilai frekuensi tertinggi juga yaitu jenis Rhizophora apiculata, sedangkan untuk nilai dominasi tertinggi dimiliki oleh jenis Sonneratia alba. Dan untuk keanekaragaman yang ada di Kampung Bahowo masih menunjukan nilai yang rendah. Kisaran suhu di Kampung Bahowo yaitu sekitar $29-30^{\circ} \mathrm{C}$, sama halnya dengan kisaran salinitas yaitu 29-30 ppt dan untuk substrat yang mendominasi yaitu berlumpur, ini yang menyebabkan jenis Rhizophora apiculata banyak ditemukan dibandingkan dengan jenis lain. .

Kata kunci: Kondisi, Mangrove, Struktur Komunitas, Kelurahan Tongkaina.

\section{PENDAHULUAN}

Mangrove merupakan beberapa jenis tumbuhan tropis maupun subtropis yang mampu bertahan hidup pada kadar salinitas air yang relatif tinggi dan substrat berlumpur. Mangrove juga merupakan tempat tinggal untuk berbagai spesies dan mampu menyediakan energi untuk berbagai organisme melalui hasil proses fotosintesis.

Umumnya ekosistem mangrove mampu tumbuh pada 4 zona, yaitu pada zona daerah terbuka, daerah tengah, dan daerah yang memiliki sungai berair payau sampai hampir 
tawar, serta daerah perbatasan dengan wilayah daratan yang memiliki air tawar. Khususnya di zona perbatasan ini ditumbuhi oleh vegetasi dari kelompok palmae yaitu jenis $\mathrm{Nypa}$ frutican.

Diketahui ada 3 fungsi utama hutan mangrove bagi kelestarian sumber daya yaitu fungsi fisik, fungsi bioekologis dan juga fungsi ekonomi yang pastinya menguntungkan bagi masyarakat maupun organisme yang berasosiasi dengan ekosistem mangrove. Secara fisik adanya hutan mangrove bisa menjadi pelindung garis pantai dari terpaan energi gelombang yang mengakibatkan abrasi, secara bioekologis ekosistim hutan mangrove merupakan tempat pemijahan dan pembesaran, tempat mencari makan, dan tempat berlindung berbagai biota laut, maupun biota darat seperti reptil, dan aves (burung). Sedangkan secara ekonomi hutan mangrove dan berbagai produk bioekologisnya mempunyai nilai ekonomi yang dapat dimanfaatkan oleh manusia sebagai bahan bangunan, bahan makanan, bahan obat-obatan, serta berpotensi sebagai obyek wisata alam (ecotourism).

\section{METODE PENELITIAN}

\section{Lokasi Penelitian}

Penelitian dilaksanakan di kawasan mangrove Kampung Bawoho, Kelurahan Tongkaina, Manado.

\section{Teknik Pengambilan Data}

Langkah awal yang dilakukan yaitu menentukan titik koordinat dan untuk titik koordinat masing-masing stasiun sebagai berikut :

- Stasiun 1, Titik koordinat $1^{\circ} 34^{\prime}$ $56^{\prime \prime} \mathrm{LU}-124^{\circ} 49^{\prime} 09^{\prime \prime}$ BT

- Stasiun 2, Titik koordinat $1^{\circ} 35^{\prime}$ $00^{\prime \prime} \mathrm{LU}$ - $124^{\circ} 49^{\prime} 17,080^{\prime}$ BT

- Stasiun 3, Titik koordinat $1^{\circ} 34^{\prime}$ $55^{\prime \prime} \mathrm{LU}$ - $124^{\circ} 49^{\prime} 01,425^{\prime \prime}$ BT

Metode yang digunakan dalam penelitian ini yaitu metode line transek kuadran yang ditarik sepanjang 100 meter pada setiap stasiun kemudian pada setiap transek diletakan/ditempatkan kuadran berukuran 10x10 m. Kemudian, pada setiap jenis tumbuhan mangrove dideterminasi dengan cara menyusuri setiap area yang sudah di blok kemudian diidentifikasi dan dihitung jumlah individu setiap jenis tumbuhan mangrove baik semai, tegakan dan pohon. Selanjutnya, dilakukan juga pengambilan data fisik lingkungan seperti pengukuran temperature, salinitas, substrat dan pasang surut.

\section{Analisis Data}

Untuk mengetahui kondisi mangrove dilakukan perhitungan Kerapatan Jenis, frekuensi jenis, Indeks Nilai Penting dan keanekaragaman sebagaimana dapat dilihat dibawah ini (Bengen, 2004).

1. Kerapatan Jenis (Di) (Bengen, 2004).

$\mathrm{Di}=\frac{\text { Jumlah total individu spesies }}{\text { Luas petak pengamatan }}$

2. Kerapatan relatif (RDi) (Bengen, 2004)

$\mathrm{RDi}=\frac{\text { Kerapatan suatu jenis }}{\text { Kerapatan seluruh jenis }} \times 100$

3. Frekuensi jenis (Fi) (Bengen, 2004)

$\mathrm{Fi}=$

Jumlah petak ditemukanya suatu jenis Jumlah seluruh plot pengamatan $\mathrm{x} 100$

4. Frekuensi relatif (RFi) (Bengen, 2004)

$\mathrm{RFi}=\frac{\text { Frekuensi suatu jenis }}{\text { Frekuensi seluruh jenis }} \times 100$

5. Penutupan jenis (Ci) (Bengen, 2004)

$\mathrm{Ci}=$

Jmlh basal area DBH jenis $i$

Luas total area pengambilan contoh (plot) $\mathrm{x} 100$ 
6. Penutupan relatif (RCi) Bengen (2004).

$$
\begin{aligned}
& \mathrm{RCi}= \\
& \frac{\text { Luas penutupan jenis ke } i}{00} \\
& \text { Total luas area penutupan seluruh jenis }
\end{aligned}
$$

7. Dari hasil perhitungan rumus diatas, kemudian dihitung indeks nilai penting (INP) dengan menggunakan rumus Bengen (2004).

$$
\mathrm{INP}=\mathrm{RDi}+\mathrm{RFi}+\mathrm{RCi}
$$

8. Keanekaragaman Odum (1971)

$$
\mathrm{H}^{\prime}=-\sum_{i=1}^{S} \frac{\mathrm{ni}}{\mathrm{N}} \operatorname{In} \frac{n i}{N}
$$

\section{HASIL DAN PEMBAHASAN}

\section{Hasil Pengambilan Data dan Komposisi Jenis}

Pengambilan data dilakukan di 3 stasiun pengamatan, dan dari hasil identifikasi terhadap mangrove yang tumbuh pada stasiun 1, pada line transek yang ditarik sepanjang $100 \mathrm{~m}$ pada 6 kuasran yang masing-masing berukuran $10 \times 10 \mathrm{~m}$ maka ditemukan ada 18 individu pada tingkat pohon dari 2 jenis yang termasuk dalam family Rhizophoraceae (Rhizophora apiculata 14 individu) dan Sonneratiaceae (Sonneratia alba 4 individu). Sedangkan pada stadia tegakan hanya ditemukan 1 dari masing-masing jenis Rhizophora apiculata dan Sonneratia alba dan untuk stadia anakan terdapat 2 individu jenis $R$. apiculata.

Hal yang sama ditunjukan leh stasiun 2 dan 3 hanya saja jumlah individu mangrove pada stadia pohon dan anakan lebih tinggi.

\section{Kerapatan Jenis dan Kerapatan Relatif}

Nilai kerapatan jenis tertinggi pada stadia pohon di stasiun 1 dimiliki oleh jenis $R$. apiculata yaitu $4.67 \mathrm{ind} / \mathrm{m}^{2}$ dan diikuti oleh jenis $S$. alba dengan nilai keraatan $1.33 \mathrm{ind} / \mathrm{m}^{2}$, sedangkan 2 jenis ini memiliki nilai Kerapatan relatif $77.78 \%$ dan $22.22 \%$.

Sedangkan di Stasiun 2 dan 3 pada jenis yang memiliki nilai kerapatan jenis tertinggi yaitu $R$. apiculata dengan masing-masing nilai $5 \mathrm{ind} / \mathrm{m}^{2}$ dan 8 ind $/ \mathrm{m}^{2}$ dan nilai kerapatan relatif masing-masing $58.54 \%$ dan $68.18 \%$.

Berbeda dengan stadia tegakan dimana nilai kerapatan tertinggi ada pada stasiun 2 yaitu jenis $S$. alba yaitu $0.07 \mathrm{ind} / \mathrm{m}^{2}$ dengan nilai kerapatan relatif $55.56 \%$, sedangkan untuk stadia anakan yang memiliki nilai kerapatan jenis tertinggi yaitu di stasiun 3 dengan nilai $0.33 \mathrm{ind} / \mathrm{m}^{2}$ ditunjukan oleh jenis $R$. apiculata dengan kerapatan relatif $50 \%$ (Gambar 1).

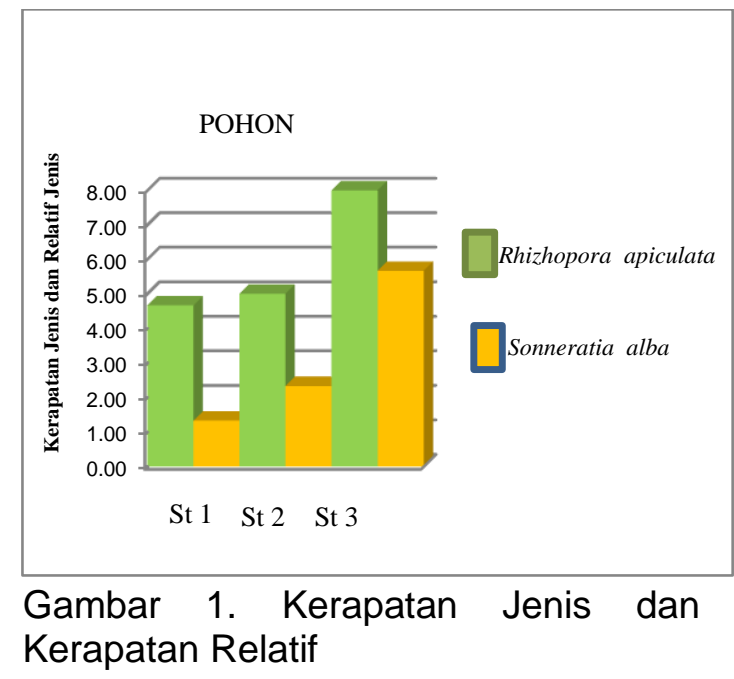




\section{Frekuensi Jenis dan Frekuensi Relatif}

Pada stadia pohon di Stasiun 1, jenis mangrove yang memiliki nilai frekuensi jenis tertinggi pada $R$. apiculata yaitu 1 dan diikuti jenis $S$. alba yaitu 0.5 dengan nilai frekuensi relatif masing-masing sebesar $0.67 \%$ dan $0.33 \%$. Sedangkan pada stasiun 2 , jenis mangrove yang memiliki nilai kerapatan jenis tertinggi yaitu $R$. apiculata dengan nilai 0.83 dengan nilai frekuensi relatif $0.63 \%$ dan pada Stasiun 3, nilai frekuensi jenis $R$. apiculata dan $S$. alba sama dengan nilai 0.88 dan frekuensi relatif $0.5 \%$.

Selanjutnya, pada stadia tegakan dan anakan pada Stasiun 1, 2 dan 3 jenis mangrove yang memiliki nilai frekuensi jenis yang tertinggi yaitu $R$. apiculata. Namun, pada stadia ankan di Stasiun 3 nilai frekuensi jenis dari $R$. apiculata dan $S$. alba sama yaitu 0.25 dengan nilai frekuensi relatif $0.5 \%$ (Gambar 2).

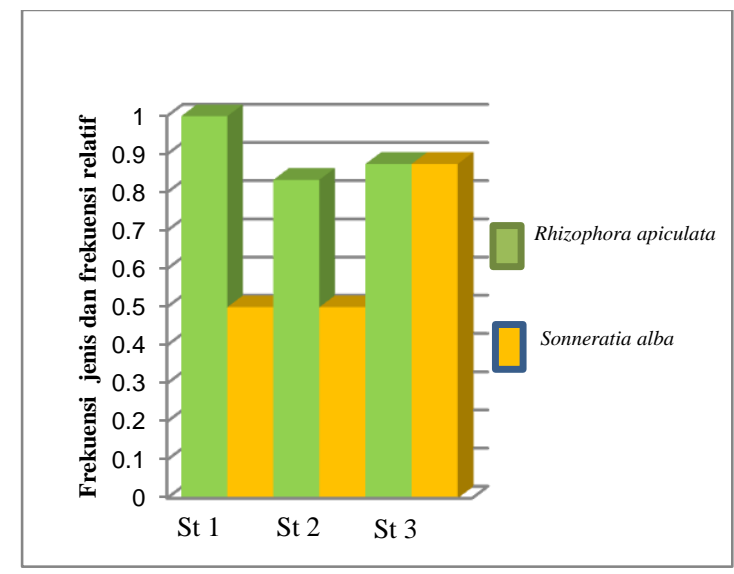

Gambar 2. Frekuensi Jenis dan Frekuensi relatif

\section{Penutupan Jenis dan Penutupan Relatif}

Penutupan jenis tertinggi pada Stasiun 1 yaitu $R$. apiculata dengan nilai $0.87 \mathrm{~m}^{2}$ dan penutupan relatif yaitu 33. 42. Kemudian pada Stasiun 2 dan 3 penutupan jenis tertinggi dimiliki $S$. alba dengan nilai $3.13 \mathrm{~m}^{2}$ dan $1.38 \mathrm{~m}^{2}$ dengan penutupan relatif yaitu $76.46 \%$ dan 64.99 \%. Sedangkan, jenis yang memiliki Nilai Penutupan Jenis yang terendah di Stasiun 1, 2, dan 3 adalah $R$. apiculata dengan nilai $0.96 \mathrm{~m}^{2}, 0,74$ $\mathrm{m}^{2}$ dan $0.87 \mathrm{~m}^{2}$. Faktor penting yang mempengaruhi Nilai Penutupan Jenis adalah lingkaran batang pohon dan basal area dalam suatu lokasi pengambilan data. Dari histogram dapat di lihat bahwa, penutupan jenis tertinggi adalah $R$. apiculata sedangkan untuk penutupan relatif nilai yang lebih tinggi ditunjukan oleh jenis $S$. alba, ini disebabkan karena lingkaran batang pohon dari jenis $S$. alba lebih besar dari pada jenis $R$. apiculata (Gambar 3 dan 4).

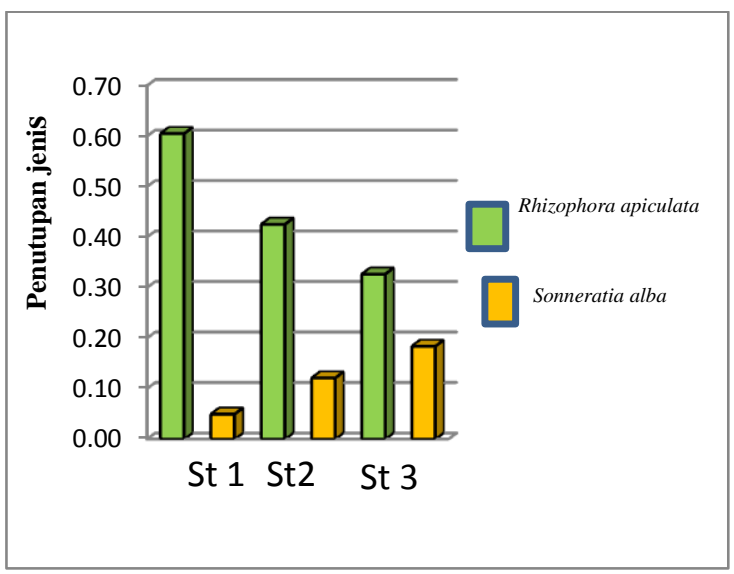

Gambar 3. Penutupan Jenis

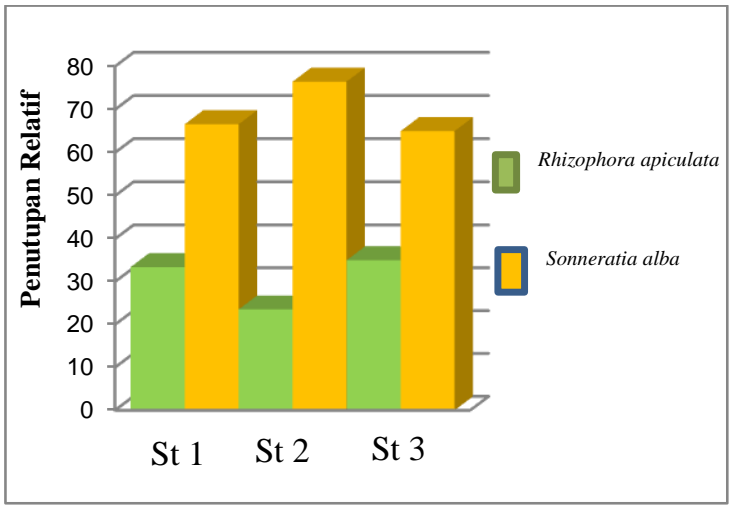

Gambar 4. Penutupan Relatif 


\section{Indeks NIlai Penting}

Indeks Nilai Penting (INP) berkisar antara 0-300 menunjukan keterwakilan jenis mangrove yang berperan dalam ekosistem sehingga jika Indeks Nilai Penting 300 berarti suatu jenis mangrove memiliki peran dan pengaruh yang penting dalam komunitas mangrove (Bengen, 2004). Hasil penelitian menunjukan bahwa pada Stasiun 2 dan 3 S. alba memiliki Indeks Nilai Penting tertinggi dan masingmasing memiliki nilai sebesar $145.05 \%$ dan $106.95 \%$. Berbeda dengan Stasiun 1, jenis $R$. apiculata memiliki Indeks Nilai penting tertinggi yaitu sebesar $13.09 \%$ (Gambar 5). Dari INP di 3 Stasiun pada skala 0-300, menunjukan bahwa peran dari $R$. apiculata dan $S$. alba dalam menjaga keberlansungan hidup ekosistem masih cukup tinggi.

Bengen (2003) mengemukakan, Indeks Nilai Penting digunakan untuk melihat pertumbuhan mangrove dalam suatu komunitas dan dari analisis kondisi vegetasi dalam komunitas mangrove.

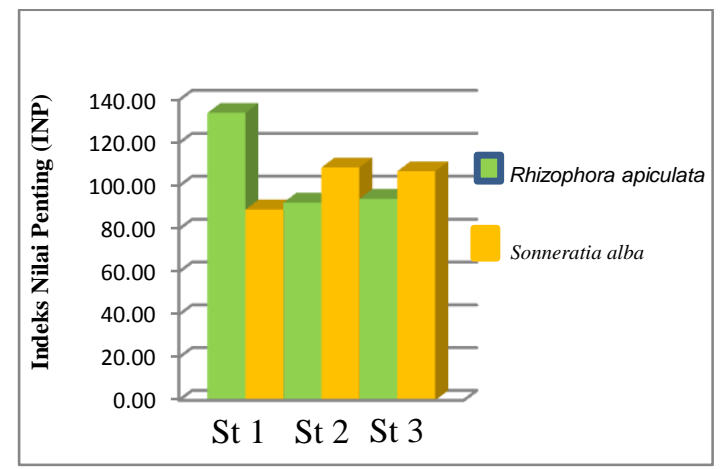

Gambar 5. Indeks Nilai Penting

\section{Keanekaragaman}

Keanekaragaman pada Stasiun 1 yaitu sebesar H' 0.53 , pada Stasiun 2 yaitu H' 0,65 kemudian pada Stasiun 3 H' 0.68 (Gambar 6). Dari ketiga Stasiun ini, Stasiun 1 yang memiliki nilai keanekaragaman terendah

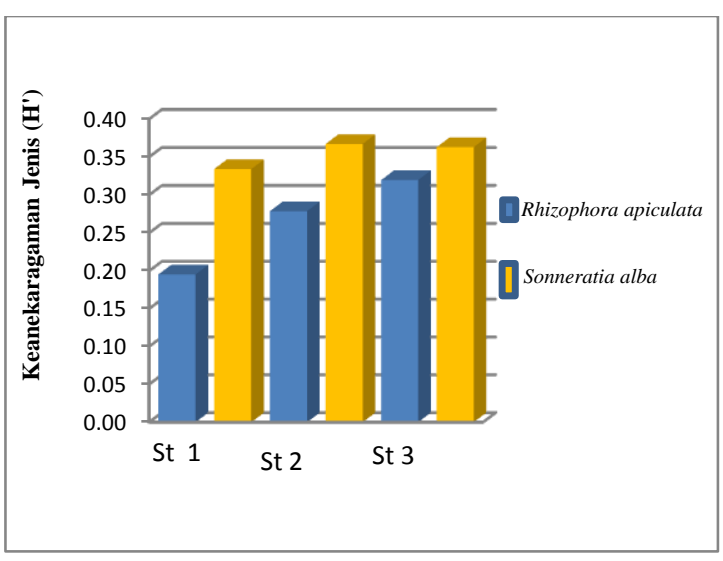

Gambar 6. Keanekaragaman

dibanding dengan Stasiun 2 dan 3 ini sebabkan oleh beberapa faktor fisikakimia.

Menurut Ludwig dan Reymond (1988), semakin besar suatu komunitas maka semakin baik pula komunitas tersebut. Dari histogram dapat terlihat bahwa hanya ada 2 jenis mangrove yang didapatkan pada lokasi penetian dan terlihat pada Stasiun 1 jenis $S$. alba lebih mendominasi di bandingkan jenis $R$. apiculata, sama halnya pada Stasiun 2 dan 3 masih tetap sama yaitu jenis Sonneratia alba yang mendominasi ini berarti bahwa keanekaragaman yang didapatkan masih kurang stabil atau kurang.

\section{KESIMPULAN}

Dari hasil penelitian disimpulkan bahwa jenis mangrove yang ada di Kampung Bahowo ada 2 jenis ditemukan yaitu $R$. apiculata dan $S$. alba. Dari ketiga stasiun penelitian juga baik kerapatan jenis dan frekuensi jenis, jenis $R$. apiculata memiliki nilai yang tertinggi tetapi untuk keanekaragaman sendiri masih rendah dan ini menunjukan kondisi ekologis yang tidak stabil. 
DAFTAR PUSTAKA

Bengen, D.G. 2003. Pedoman Teknis Pengenalan dan Pengelolaan Ekosistem Mangrove.Pusat Kajian Sumberdaya Pesisir dan Laut-Institut Pertanian Bogor. Bogor.

Bengen, D.G. 2004. Pedoman teknis: Pengenalan dan pengelolaan ekosistem mangrove. PKSPLIPB. Bogor.

Ludwig, J.A., Reynold, J.F. 1988. Statistical Ecology. A Primer on Method and Computing. A Willey Interscience Publication New York.338 hal.

Odum, E.P. 1971. Dasar-Dasar Ekologi. Edisi ketiga Gadjah Mada University Press. Yogyakarta. 697 hal. 